\title{
Mixed-methods approaches in health research in Nepal
}

\section{Simkhada P1-6, van Teijlingen E5-7, Wasti SP8, Sathian B9}

1 Professor of International Public Health, Centre for Public Health, Liverpool John Moores University, UK

2 Honorary Senior Lecturer, School of Health and Related Research (ScHARR), University of Sheffield, Sheffield

3 Visiting Fellow, Bournemouth University, UK.

${ }^{4}$ Adjunct Faculty- Datta Meghe Institute of Medical Sciences (Deemed University) Nagpur, India

5 Visiting Professor, Manmohan Institute of Health Science, Tribhuvan University, Nepal.

${ }^{6}$ Visiting Professor, Nobel College, Pokhara University, Kathmandu, Nepal.

7 Professor, School of Health \& Social Care, Bournemouth University, Bournemouth, UK.

${ }^{8}$ Editorial Board Member, Nepal Journal of Epidemiology, Nepal

${ }^{9}$ Assistant Professor, Manipal College of Medical Sciences, Pokhara, Nepal.

\section{Chief Editor}

\section{Dr. Pradeep Aggarwal}

\section{Technical Editor}

Dr. Nishida Chandrasekharan

Formatting Editor

Dr. Ram Lakhan

\section{Editorial}

Corresponding Author

Prof Padam Simkhada

Professor of International Public Health, Liverpool John Moores University, UK

E-mail: p.p.simkhada@ljmu.ac.uk

\section{Abstract}

Combining and integrating a mixture of qualitative and quantitative methods in one single study is widely used in health and social care research in high-income countries.
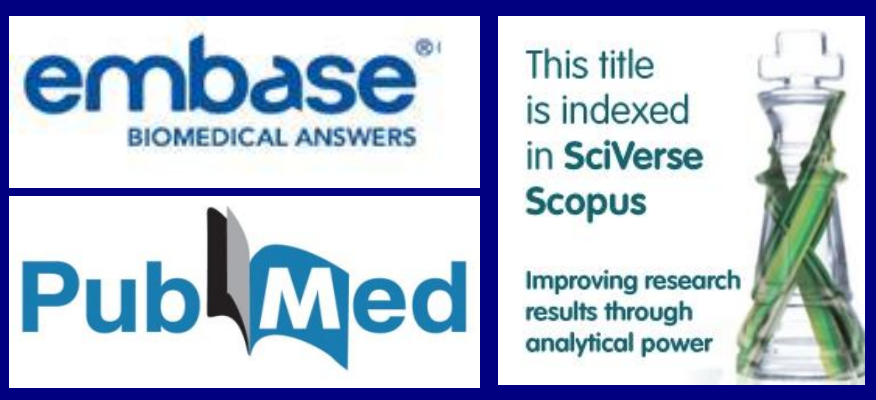

This editorial adds a few words of advice to the novice mixed-methods researcher in Nepal.

Keywords: Quantitative research; Qualitative researchs; Mixed Methods Research

\section{Background}

This latest issue of the Nepal Journal of Epidemiology carries an instructive research-methods article on the mixedmethods approach by MacKenzie Bryers and colleagues ${ }^{1}$. The paper gives researchers, academic teachers, policy makers and people working for funding bodies and development organisations a better insight into the strengths and weaknesses of the mixed-methods approach. Combining and integrating a mixture of qualitative and quantitative methods in one single study is widely used in 
health and social care research in high-income countries. The paper outlines the various ways of combining methods and methodological issues that need to be considered.

This editorial adds a few words of advice to the novice mixed-methods researcher in Nepal. First we like to highlight is that you need to be an expert in two different methods or at least get a research team together that includes experts in both qualitative and quantitative research. It sounds like an obvious piece of advice but too often we see quantitative researchers who think they can do a bit of interviewing as well or run a few focus groups. The key problem with such opportunistic approach is that the researcher often lacks (a) insight into underlying philosophy and (b) the skills to apply the method appropriately.

Secondly, researchers need to plan beforehand how they are going to integrate the qualitative and quantitative research findings in the final analysis and how they are going to present it in the final report. We offer an example of good practice from a longitudinal study of an intervention aiming to improve maternity care in a rural part of $\mathrm{Nepal}^{2}$. The evaluation study was designed as non-randomized and before-and-after-study with a controlled group using a mixed-methods approach ${ }^{3}$. It was based on the notion that the effects of an intervention would be assessed by collecting quantitative both before and after the maternity care intervention was introduced. The results for the control and intervention groups were then compared statistically. In order to make the results comparable, the methodology and the data collection tools adopted in the final survey before were similar to those used in the baseline survey. The qualitative research followed a similar pattern in terms of data collection, views and perceptions of people in the community who were or could have been influenced by the intervention were collected before, during and after the intervention to help explain any statistically significant findings in the quantitative research or even lack thereof.

Thirdly, this editorial provides some key references ${ }^{3,4}$ to help understand and apply the mixed-methods approach and some reference to other studies in Nepal, for example conducted in the field of education ${ }^{5}$ or costs of maternity care to service-users ${ }^{6}$. A study of HIV service users used a cross-sectional mixed-methods approach, with a quantitative survey of 330 people living with HIV patients and 34 qualitative interviews with three different types of stakeholders: patients, care providers, and key people at policy level. A multivariate logistic regression model was used to identify factors associated with adherence, supplemented with a thematic analysis of the interviews ${ }^{7}$. The studies highlighted as an example indicate the range of mixed-methods approaches applied in health and health care studies in Nepal.

\section{Conflict of interest:}

None

\section{References}

1. MacKenzie Bryers $H$, van Teijlingen $E$, Pitchforth $E$. Mixed-methods in health research. Nepal Journal of Epidemiology 2014; 4(5):417-22.

2. van Teijlingen E, Simkhada P, Stephen J, Simkhada B, Woodes Rogers S, Sharma S. Making the best use of all resources: developing a health promotion intervention in rural Nepal. Health Renaissance 2012; 10(3): 229-235. www.healthrenaissance.org.np/uploads/7141_24852_1_PB .pdf

3. Creswell JW, Plano Clark VL. Designing and conducting mixed methods research. Thousand Oaks, CA: Sage, 2007.

4. Plano Clark V L, Creswell JW. The mixed methods reader. Thousand Oaks, CA: Sage, 2008.

5. Simkhada $P$, van Teijlingen $E$, Devkota $B$, Pathak RS, Sathian B. Accessing research literature: A mixed-method study of academics in Higher Education Institutions in Nepal. Nepal Journal of Epidemiology 2014; 4(4): 405-14 http://dx.doi.org/10.3126/nje.v4i4.11375

6. Simkhada P, van Teijlingen E, Sharma G, Simkhada B, Townend J. User costs and informal payments for care in the largest maternity hospital in Kathmandu, Nepal. Health Science Journal, 2012; 6(2): 327-334

7. Wasti S P, Simkhada P, Randall J, Freeman J V, van Teijlingen $E$. Factors influencing adherence to antiretroviral treatment in Nepal: A mixed-methods study. PLoS ONE, 2012;7(5).

http://dx.doi.org/10.1371/journal.pone.0035547

PMid:22563464 PMCid:PMC3341373

Article Information

Article history

Received

$12^{\text {th }}$ December 2014

Received in revised form

$15^{\text {th }}$ December 2014

Accepted

$28^{\text {th }}$ December 2014 